\title{
Conflicting results obtained by RAPD-PCR and large-subunit rDNA sequences in determining and comparing yeast strains isolated from flowers: a comparison of two methods
}

\footnotetext{
${ }^{1}$ Plant Ecology, Department of Biology, PhilippsUniversity Marburg, Karl-von-Frisch-Straße, 35043 Marburg, Germany

2 Department of Biology, Philipps-University Marburg and Department of Biochemistry, MaxPlanck-Institut, Karlvon-Frisch-Straße, 35043 Marburg, Germany
}

\author{
Michael Herzberg, ${ }^{1}$ Reinhard Fischer ${ }^{2}$ and Andreas Titze ${ }^{1}$ \\ Author for correspondence: Michael Herzberg. Tel: +49 6421282 2054. Fax: +496421 2822093. \\ e-mail: Herzberg@stud-mailer.uni-marburg.de
}

\begin{abstract}
Sixty-six yeast strains isolated from the nectar of various plant species in Central Europe were characterized by randomly amplified polymorphic DNA PCR (RAPD-PCR) and by sequencing of the variable D1/D2 domain of largesubunit (26S) rDNA. The usefulness of both methods for the determination and comparison of unknown ascomycetous and basidiomycetous yeast strains was compared and evaluated. The reproducibility of RAPD-PCR was shown to be low and the information obtained by this method was clearly not as precise as that obtained from sequence analysis. Numerous imponderables make RAPDPCR analysis unreliable, at least as a means of identifying yeasts in ecological studies. The lack of standard protocols for RAPD-PCR analysis and the absence of a general database of banding patterns made it impossible to identify unknown yeast strains or to recognize new species. In contrast to RAPD-PCR, sequence analysis of the D1/D2 domain was found to be a fast and reliable method for the rapid identification of yeast species and was also shown to be an invaluable tool for the discovery of new species.
\end{abstract}

Keywords: 26S rDNA, nectar, sequence analysis, yeasts, RAPD-PCR

\section{INTRODUCTION}

The occurrence of yeasts in floral nectaries was first reported by Boutroux (1881). Various authors, such as Boutroux (1884), Reukauf (1911/12), Schuster \& Úhlela (1913), Grüß (1917/18), Sydow \& Sydow (1918), Schoellhorn (1919) and Hautmann (1924), have since described nectar yeast morphologically and have introduced numerous synonyms of Metschnikowia gruessii Giménez-Jurado and Metschnikowia reukaufii Pitt \& Miller. Hence, it became clear that the use of morphological characteristics as an aid to species identification is limited in yeast taxonomy (StellingDekker, 1931). In other investigations, physiological tests were used to characterize strains of nectar yeasts (Grüß, 1927; Martin, 1954). At least for members of the genus Metschnikowia Kamienski, which contains several species associated with flowers, classi-

Abbreviations: CBS, Centraalbureau voor Schimmelcultures; RAPD, randomly amplified polymorphic DNA.

The GenBank accession numbers for the 26S rDNA sequences reported in this paper can be found in Table 1 . fication based on physiological properties turned out to be ineffective (Pitt \& Miller, 1970).

Even in more recent studies there seems to be confusion about the identity of nectar yeast strains. Eiskowitch et al. (1990) reported that, in an ecophysiological study on nectar yeasts, two strains identified as $M$. reukaufii were clearly different in their physiological properties. One of the strains exhibited 'airplane' cell configurations that are characteristic of $M$. gruessii, whereas the other strain was 'more typical' of $M$. reukaufii, suggesting that the two strains did not belong to the same species. Even though $M$. gruessii had not been described at the time of the study by Eiskowitch and colleagues, the example shows that a fast, simple and reliable method for yeast identification is necessary in yeast ecology.

Price et al. (1978) showed genome comparison to be a valuable tool in yeast classification. Williams et al. (1990) and Welsh \& McClelland (1990) developed the randomly amplified polymorphic DNA PCR (RAPDPCR) and arbitrarily primed PCR (AP-PCR) methods, respectively, as simple tools to aid in classification. 
Table 1. Yeasts isolated from the nectar of different flowering plant species

\begin{tabular}{|c|c|c|c|c|c|}
\hline $\begin{array}{l}\text { Site/date of } \\
\text { sampling }\end{array}$ & Host & Yeast species & UM* no. & CBS $\dagger$ no. & $\begin{array}{c}\text { GenBank } \\
\text { accession no. }\end{array}$ \\
\hline \multicolumn{6}{|l|}{ Marburg: } \\
\hline \multirow[t]{2}{*}{$21 / 04 / 99$} & Arabis alpina & Cryptococcus heveanensis sister (37st) & MH 40 & CBS 8976 & AF406890 \\
\hline & & Rhodotorula bacarum & MH 46 & CBS 8977 & AF406891 \\
\hline $21 / 04 / 99$ & Arctostaphylos uva-ursi & Metschnikowia reukaufii§ & MH 120 & CBS 8978 & - \\
\hline $02 / 06 / 99$ & Atropa bella-donna & Cryptococcus victoriae sister (12s) & MH 39 & CBS 8979 & AF406892 \\
\hline $04 / 06 / 99$ & Ballota nigra & Cryptococcus oeirensis & MH 38 & CBS 8980 & AF406902 \\
\hline $22 / 08 / 99$ & Epilobium angustifolium & Metschnikowia reukaufii§ & MH 105 & CBS 8981 & - \\
\hline $25 / 08 / 99$ & Epilobium angustifolium & Cryptococcus albidus & MH 6 & CBS 8982 & AF406903 \\
\hline $25 / 08 / 99$ & Epilobium angustifolium & Cryptococcus albidus & MH 20 & CBS 8983 & AF406904 \\
\hline $25 / 08 / 99$ & Epilobium angustifolium & Cryptococcus diffluens & MH 4 & CBS 8984 & AF406907 \\
\hline $25 / 08 / 99$ & Epilobium angustifolium & Cryptococcus diffluens & MH 148 & CBS 8985 & AF406908 \\
\hline $25 / 08 / 99$ & Epilobium angustifolium & Rhodotorula mucilaginosa & MH 146 & CBS 8986 & AF406910 \\
\hline $26 / 08 / 99$ & Epilobium angustifolium & Rhodotorula mucilaginosa & MH 147 & CBS 8987 & AF406911 \\
\hline $26 / 08 / 99$ & Epilobium angustifolium & Cryptococcus diffluens & MH 11 & CBS 8988 & AF406905 \\
\hline 26/08/99 & Epilobium angustifolium & Cryptococcus albidus & MH 103 & CBS 8989 & AF406906 \\
\hline $26 / 08 / 99$ & Epilobium angustifolium & Cryptococcus diffluens & MH 159 & CBS 8990 & AF406909 \\
\hline $27 / 08 / 99$ & Epilobium angustifolium & Metschnikowia gruessii§ & MH 19 & CBS 8991 & - \\
\hline $16 / 04 / 99$ & Erica carnea & Cystofilobasidium capitatum & MH 30 & CBS 8992 & AF406887 \\
\hline $15 / 04 / 99$ & Euphorbia amygdaloides & Cryptococcus victoriae sister (8s) & MH 23 & CBS 8993 & AF408633 \\
\hline $10 / 04 / 99$ & Helleborus foetidus & Metschnikowia reukauffii & MH 139 & CBS 8994 & AF406915 \\
\hline $10 / 04 / 99$ & Helleborus foetidus & Metschnikowia reukauffii§ & MH 104 & CBS 8995 & - \\
\hline $10 / 04 / 99$ & Helleborus foetidus & Metschnikowia reukauffii§ & MH 128 & CBS 8996 & - \\
\hline $15 / 04 / 99$ & Helleborus foetidus & Metschnikowia reukauffii & MH 101 & CBS 8997 & AF406916 \\
\hline $12 / 02 / 00$ & Helleborus foetidus & Saccharomyces servazzii & MH 158 & CBS 8998 & AF406921 \\
\hline $21 / 02 / 00$ & Helleborus foetidus & Cryptococcus victoriae sister (12s) & MH 166 & CBS 8999 & AF406893 \\
\hline $21 / 02 / 00$ & Helleborus foetidus & Unknown§ & MH 168 & - & - \\
\hline $21 / 02 / 00$ & Helleborus foetidus & Cryptococcus victoriae & MH 152 & CBS 9000 & AF406899 \\
\hline $16 / 02 / 00$ & Helleborus foetidus & Cystofilobasidium capitatum $§$ & MH 167 & CBS 9001 & - \\
\hline $01 / 03 / 00$ & Helleborus foetidus & Rhodosporidium lusitaniae sister (11s) & MH 150 & CBS 9002 & AF406922 \\
\hline $05 / 03 / 00$ & Helleborus foetidus & Cystofilobasidium capitatum & MH 153 & CBS 9003 & AF406887 \\
\hline \multirow[t]{3}{*}{$08 / 03 / 00$} & Helleborus foetidus & Cystofilobasidium capitatum & MH 161 & CBS 9004 & AF406888 \\
\hline & & Cryptococcus cylindricus & MH 160 & CBS 9005 & AF406933 \\
\hline & & Cryptococcus victoriae & MH 155 & CBS 9006 & AF406900 \\
\hline \multirow[t]{3}{*}{ 08/03/00 } & Helleborus foetidus & Cryptococcus laurentii sister (10s) & MH 164 & CBS 9007 & AF406934 \\
\hline & & Filobasidium globisporum (3s) & MH 149 & CBS 9008 & AF406932 \\
\hline & & Cryptococcus victoriae & MH 156 & CBS 9009 & AF406901 \\
\hline $08 / 03 / 00$ & Helleborus foetidus & Cystofilobasidium capitatum & MH 154 & CBS 9010 & AF406889 \\
\hline $09 / 03 / 00$ & Helleborus foetidus & Filobasidium globisporum (3s) & MH 157 & CBS 9011 & AF406931 \\
\hline \multirow[t]{3}{*}{$09 / 03 / 00$} & Helleborus foetidus & Cryptococcus victoriae sister (8s) & MH 162 & CBS 9012 & AF406894 \\
\hline & & Cryptococcus victoriae sister (2s) & MH 151 & CBS 9013 & AF406895 \\
\hline & & Cystofilobasidium capitatum & MH 163 & CBS 9014 & AF406885 \\
\hline 20/04/99 & Lamium album & Sporobolomyces ruberrimus & MH 134 & CBS 9015 & AF406930 \\
\hline $18 / 04 / 99$ & Lamium purpureum & Metschnikowia reukaufii & MH 28 & CBS 9016 & AF406917 \\
\hline $06 / 04 / 99$ & Primula elatior & Candida bombi & MH 21 & CBS 9017 & AF406929 \\
\hline $15 / 04 / 99$ & Prunus spinosa & Metschnikowia reukaufii§ & MH 31 & CBS 9018 & - \\
\hline \multirow[t]{2}{*}{$16 / 04 / 99$} & Pulmonaria officinalis & Metschnikowia reukaufii§ & MH 32 & CBS 9019 & - \\
\hline & & Metschnikowia reukaufii§ & MH 119 & - & - \\
\hline \multirow[t]{2}{*}{$17 / 04 / 99$} & Pulmonaria officinalis & Metschnikowia reukaufii & MH 131 & CBS 9020 & AF406918 \\
\hline & & Metschnikowia reukaufii & MH 132 & CBS 9021 & AF406919 \\
\hline $17 / 04 / 99$ & Pulmonaria rubra & Metschnikowia reukaufii & MH 133 & CBS 9022 & AF406920 \\
\hline $06 / 04 / 99$ & Pulmonaria stiriaca & Cryptococcus victoriae sister (8s) & MH 33 & CBS 9023 & AF406896 \\
\hline $18 / 04 / 99$ & Ranunculus bulbosus & Cryptococcus victoriae sister (12s) & MH 27 & CBS 9024 & AF406897 \\
\hline $18 / 04 / 99$ & Ranunculus ficaria & Cryptococcus victoriae sister (12s) & MH 13 & CBS 9025 & AF406898 \\
\hline
\end{tabular}


Table 1 (cont.)

\begin{tabular}{|c|c|c|c|c|c|}
\hline $\begin{array}{l}\text { Site/date of } \\
\text { sampling }\end{array}$ & Host & Yeast species & UM* no. & CBS $\dagger$ no. & $\begin{array}{c}\text { GenBank } \\
\text { accession no. }\end{array}$ \\
\hline 08/04/99 & Rhododendron maximum & Cystofilobasidium capitatum & MH 1 & CBS 9026 & AF406885 \\
\hline $08 / 04 / 99$ & Rhododendron sulchuenense & Rhodotorula fujisanensis & MH 2 & CBS 9027 & AF406928 \\
\hline $08 / 04 / 99$ & Rhododendron sulchuenense & Rhodosporidium lusitaniae sister (11s) & MH 47 & CBS 9028 & AF406923 \\
\hline \multirow[t]{2}{*}{$02 / 06 / 99$} & Symphytum officinale & Metschnikowia gruessii§ & MH 41 & CBS 9029 & - \\
\hline & & Metschnikowia gruessii§ & MH 129 & - & - \\
\hline \multirow[t]{2}{*}{$27 / 05 / 99$} & Trifolium pratense & Metschnikowia gruessii§ & MH 137 & CBS 9030 & - \\
\hline & & Metschnikowia gruessii & MH 138 & CBS 9031 & AF406912 \\
\hline \multicolumn{6}{|l|}{ Mainz: } \\
\hline $04 / 06 / 99$ & Vicia villosa & Cryptococcus macerans & MH 45 & CBS 9032 & AF406924 \\
\hline $04 / 06 / 99$ & Salvia pratensis & Metschnikowia gruessii & MH 53 & CBS 9033 & AF406913 \\
\hline \multirow[t]{3}{*}{ 03/06/99 } & Rhinanthus alectorolophus & Metschnikowia gruessii & MH 127 & - & AF406914 \\
\hline & & Metschnikowia gruessii§ & MH 102 & - & \\
\hline & & Sporobolomyces roseus sister (4s) & MH 165 & CBS 9035 & AF406925 \\
\hline \multirow[t]{2}{*}{ 03/06/99 } & Anchusa officinalis & Metschnikowia hibisci sister (4s) & MH 122 & CBS 9036 & AF406926 \\
\hline & & $\begin{array}{l}\text { Metschnikowia continentalis var. } \\
\text { continentalis }\end{array}$ & MH 124 & CBS 9037 & AF406927 \\
\hline
\end{tabular}

* UM, strains from the University of Marburg.

$\dagger$ CBS, strains from the Centraalbureau voor Schimmelcultures.

\$ A lower-case s with a number in parentheses indicates the number of substitutions in the D1/D2 domain compared to the type strain of the closest related species.

$\S$ Strains that were only identified by morphological characteristics and not by sequencing.

These methods are based on the random amplification of DNA to characterize species and individuals by banding patterns. Since both methods were developed simultaneously and work on the same principle, the more common term RAPD-PCR is used for both techniques in the current study. Guadet et al. (1989) and O'Donnell (1993) developed a method to identify and characterize fungal species and strains by analysing the sequence of the D1/D2 divergent domain of large-subunit (26S) rDNA. Both DNA sequence analysis (e.g. Kurtzman \& Robnett, 1997, 1998; Fell et al., 2000; Lachance et al., 2001) and RAPD-PCR (e.g. Messner et al., 1994; Mollnár et al., 1995; Lopandic et al., 1996; Romano et al., 1996; Prillinger et al., 1999; Ganter \& de Barros Lopes, 2000; Paramithiotis et al., 2000; Naumova et al., 2000) have been used frequently in the characterization and determination of yeast strains.

The initial aim of this study was to use RAPD-PCR to simplify the identification of more than 200 yeast strains isolated from the nectar of various plant species in Europe. As the ambiguity of the RAPD-PCR results became apparent, D1/D2 sequences were determined for 65 yeast strains. This allowed a critical comparison of the two approaches to be made.

\section{METHODS}

Yeast isolation and purification. The strains considered in this study are listed in Table 1. Most samples were collected in Marburg and from the surrounding area (i.e. an area of a few kilometres). Another group of samples was collected near Mainz. The collections were made from April to August 1999 and from January to March 2000. All samples came from the nectar of the floral nectaries of various plant species. Nectar was collected from the plants by using sterile Pasteur capillary pipettes. This was then plated directly onto $40 \%(\mathrm{w} / \mathrm{w})$ sugar agar $\left(0 \cdot 2 \%, \mathrm{w} / \mathrm{w}, \mathrm{MgSO}_{4} ; 0 \cdot 3 \%\right.$, w/w, $\mathrm{KH}_{2} \mathrm{PO}_{4} ; 0.5 \%$, w/w, peptone; $13.3 \%$, w/w, sucrose; $13 \cdot 3 \%$, w/w, glucose; $13 \cdot 3 \%$, w/w, fructose; $2 \%$, w/w, agar), as described by Hautmann (1924). The strains were further purified by cross-streaking them onto $10 \%(\mathrm{w} / \mathrm{w})$ malt extract agar. Single-cell cultures were produced according to the method of Vobis (1992). Most of the strains have been deposited at the Centraalbureau voor Schimmelcultures (CBS), Oosterstraat 1, Baarn, The Netherlands.

Morphological characterization. To obtain more morphological characteristics, the strains were cultivated on GY agar $(1 \%, \mathrm{w} / \mathrm{w}$, glucose; $0.01 \%$, w/w, yeast extract; $2 \%$, w/w, agar; Lachance \& Pang, 1997), dilute Gorodkowa agar $(1 \mathrm{~g}$ glucose, $5 \mathrm{~g} \mathrm{NaCl}, 10 \mathrm{~g}$ peptone, $20 \mathrm{~g}$ agar in $11 \mathrm{of}$ tap $\mathrm{H}_{2} \mathrm{O}$; Lodder \& Kreger-van Rij, 1952) and dilute V8 agar (Pitt \& Miller, 1968). Gorodkowa and V8 media were diluted $1: 10,1: 15,1: 30$ and $1: 100(\mathrm{v} / \mathrm{v})$. The cultures were incubated at $14{ }^{\circ} \mathrm{C}$. To observe the germination of cultures of Cystofilobasidium capitatum (Fell, Hunter \& Tallman) Oberwinkler et al. that were rich in teliospores, slide cultures were incubated on YM at $18^{\circ} \mathrm{C}$.

Microscopy. For scanning electron microscopy, the cultures were prepared according to the methods of Vobis (1991). The samples were observed with a Hitachi S-530 microscope. Phase-contrast microscopy was performed using a Leitz Ortholux microscope. Cells were spread over a thin agar slab (Lachance, 1987). Images were recorded electronically.

DNA isolation. DNA was isolated from 24-h-old liquid cultures using the DNeasy Plant Mini Kit (Qiagen). The 
DNA concentration and its purity was measured with an Ultraspec 3100 pro Photometer (Amersham Pharmacia Biotech). For each sample, the DNA concentration was adjusted to $10 \mathrm{ng} \mu \mathrm{l}^{-1}$.

RAPD assay. PCR was performed in $0.5 \mathrm{ml}$ thermo-tubes (Advanced Biotechnologies) using a TRIO-Thermoblock (Biometra). Three microlitres of DNA solution $\left(10 \mathrm{ng} \mu \mathrm{l}^{-1}\right)$ and $27 \mu \mathrm{l}$ of PCR master mix were mixed in a thermo-tube and overlaid with $35 \mu \mathrm{l}$ of mineral oil (Sigma-Aldrich Chemie).The PCR master mix contained $30 \mu \mathrm{l}$ sterile bidistilled $\mathrm{H}_{2} \mathrm{O}, 10 \times$ buffer $(200 \mathrm{mM}$ Tris $/ \mathrm{HCl}, 500 \mathrm{mM}$ $\mathrm{KCl}$; $\mathrm{pH} 8.4$ ) added to a final concentration of $1 \times, 3 \mathrm{mM}$ $\mathrm{MgCl}_{2}, 0 \cdot 16 \mathrm{mM}$ of each dNTP, 5 U Taq DNA Polymerase (Gibco-BRL) and $0.5 \mathrm{pM}$ of primer. The following primers were synthesized by MWG-Biotech : 1, 5'-ACGGTCTTGG3'; 2, 5'-TGCAGCGTGG-3'; 3, 5'-GGGTAACGCC-3'. The primers were as suggested by Lopandic et al. (1996). The PCR protocol used was as follows. After a $10 \mathrm{~min}$ denaturation at $95^{\circ} \mathrm{C}$, the PCR was subjected to 35 cycles at $94{ }^{\circ} \mathrm{C}$ for $15 \mathrm{~s}, 40^{\circ} \mathrm{C}$ for $30 \mathrm{~s}$ and $72{ }^{\circ} \mathrm{C}$ for $2 \mathrm{~min}$, with a final extension at $72{ }^{\circ} \mathrm{C}$ for $5 \mathrm{~min}$.

Twenty-five microlitres of the PCR product was mixed with $5 \mu 1 \mathrm{H}_{2} \mathrm{O}$ and $3 \mu \mathrm{l} 10 \times$ loading buffer. The DNA fragments were analysed in a $2 \%(\mathrm{w} / \mathrm{v})$ agarose gel in $1 \times$ TAE buffer; the electrophoresis unit was run at $90 \mathrm{~V}$ for $3 \mathrm{~h}$. A $500 \mathrm{bp}$ ladder (Qbiogene) and a $100 \mathrm{bp}$ ladder (MBI fermentas) were included in every fifth lane in every gel. The gels were stained with ethidium bromide for $1 \mathrm{~h}$ and then photographed under UV light ( $\lambda 360 \mathrm{~nm}$ ). The gel images were recorded digitally and saved as TIFF files.

The digitized images were inverted and imported into the GelCompar II software (Applied Maths) (Rademaker et al., 1999). The gels were normalized using the molecular size marker. Similarity matrices of the densitometric curves of the gel lanes were calculated using the pair-wise Pearson's correlation coefficient (Häne et al., 1993). 'Active zones' were defined on the images, so that the beginning and end of each lane where no bands could be observed were excluded from the analyses to minimize the background (Vinuesa et al., 1998). Cluster analysis of similarity matrices was performed by using the neighbour-joining algorithm.

The type strains of Metschnikowia pulcherrima Pitt \& Miller (CBS 5833 ${ }^{\mathrm{T}}$ ), Metschnikowia lunata Golubev (CBS 5946 ${ }^{\mathrm{T}}$ ), Metschnikowia agaves Lachance (CBS $7745^{\mathrm{T}} \mathrm{h}^{-}$), Metschnikowia continentalis var. continentalis Lachance et al. (CBS $8429^{\mathrm{T}} \mathrm{h}^{+}$, CBS $8430^{\mathrm{T}} \mathrm{h}^{-}$), Metschnikowia continentalis var. borealis Lachance et al. (CBS $8431^{\mathrm{T}} \mathrm{h}^{+}$, CBS $\left.8432^{\mathrm{T}} \mathrm{h}^{-}\right)$, Metschnikowia hibisci Lachance et al. (CBS $8433^{\mathrm{T}} \mathrm{h}^{+}$, CBS $8434^{\mathrm{T}} \mathrm{h}^{-}$), Metschnikowia hawaiiensis Lachance, Starmer \& Phaff (CBS $7432^{\mathrm{T}} \mathrm{h}^{+}$) and Candida kofuensis Mikita et al. $\left(\mathrm{CBS} 8058^{\mathrm{T}}\right)$ were used as reference materials. As reference material for M. gruessii Giménez-Jurado we used the original strain of Grüß (1917/18) (CBS 611), for M. reukaufii Pitt \& Miller we used strain CBS 1903 and for M. pulcherrima Pitt \& Miller we used CBS 610.

DNA sequence analysis. The sequence of the D1/D2 domain of the large-subunit rDNA for each sample (Table 1) was directly determined by sequencing the PCR products. Primers NL1 (5'-GCATATCAATAAGCGGAGGAAAAG-3') and NL4 (5'-GGTCCGTGTTTCAAGAC-GG-3') (O’Donnell, 1993) were used. The primers were synthesized by MWG Biotech. PCR was performed as specified above, but with the following changes. The PCR master mix contained $30 \mu \mathrm{l}$ sterile bi-distilled $\mathrm{H}_{2} \mathrm{O}, 10 \times$ buffer (Tris/ $\mathrm{HCl} 200 \mathrm{mM}, 500 \mathrm{mM} \mathrm{KCl}$; $\mathrm{pH} \mathrm{8.4)} \mathrm{added} \mathrm{to} \mathrm{a} \mathrm{final}$ concentration of $1 \times, 1.5 \mathrm{mM} \mathrm{MgCl}_{2}, 0.25 \mathrm{mM}$ of each
dNTP, 5 U Taq DNA Polymerase, 0.33 pM of primer NL1 and $0.33 \mathrm{pM}$ of primer NL4. After a 2 min denaturation at $95^{\circ} \mathrm{C}$, the PCR was subjected to 35 cycles at $95^{\circ} \mathrm{C}$ for $15 \mathrm{~s}$, $64{ }^{\circ} \mathrm{C}$ for $25 \mathrm{~s}$ and $72{ }^{\circ} \mathrm{C}$ for $2 \mathrm{~min}$, with a final extension at $72{ }^{\circ} \mathrm{C}$ for $5 \mathrm{~min}$.

Sequencing was done by MWG Biotech. The sequences for the strains were deposited in GenBank. The CLUSTAL w algorithm (Thompson et al., 1994) was used to align the sequences and to construct a neighbour-joining tree. Bootstrap re-sampling was performed for the tree (1000 replications). The sequence of the type strain for each species was downloaded from GenBank and included in the analysis.

\section{RESULTS AND DISCUSSION}

All yeast strains, their CBS numbers, GenBank accession numbers, hosts of the strains and the dates of sampling are listed in Table 1. Ascomycetous yeasts belonging to the genera Candida Berkout, Metschnikowia and Saccharomyces Meyen ex Rees were found in the samples, as well as numerous basidiomycetous species belonging to the genera Cryptococcus Vuillemin, Cystofilobasidium Oberwinkler et al. Filobasidium Olive, Rhodosporidium Banno, Rhodotorula Harrison and Sporobolomyces Kluyver \& van Niel.

\section{Morphological characterization}

Of the ascomycetes, $M$. reukauffii $(n=13)$ and $M$. gruessii $(n=7)$ were found most often in the samples. In most cases, these two species could be distinguished on GY agar; M. gruessii produced its characteristic elongated 'airplane' or trident configurations when grown on this agar (Grüß, 1917/18; Giménez-Jurado, 1992), whereas these were absent in M. reukaufii. On dilute, filtered V8 $(1: 15 ; 1: 30)$ the two species could be distinguished by their chlamydospores, which were oval for $M$. gruessii and elongated for $M$. reukaufii. Additional morphological characteristics as described by Giménez-Jurado (1992) - e.g. the formation of thin pseudohyphae with terminal conidia or rich branched pseudomycelium formed by cylindrical cells on $10 \%$ malt extract agar - turned out not to be very helpful in distinguishing $M$. gruessii and $M$. reukaufii because these characteristics were only temporarily observed in some strains.

Of the basidiomycetous yeasts, Cystofilobasidium capitatum $(n=8)$ was most often found and this species could be confidently identified on the basis of morphological characteristics. On all media used in this study, cultures more than one month old exhibited pseudomycelium and true uninucleate mycelium with lateral, terminal or intercalary teliospores. Teliospores could also be observed without the formation of true mycelium. In contrast to the findings of Oberwinkler $e t$ al. (1983), these teliospores often germinated by the formation of septated true mycelium. Soaking the teliospores in $\mathrm{H}_{2} \mathrm{O}$ for a prolonged period of time, as described by Kwong-Chung (1998), was not required for germination; the teliospores germinated after $8 \mathrm{~h}$ in slide cultures grown on YM. 


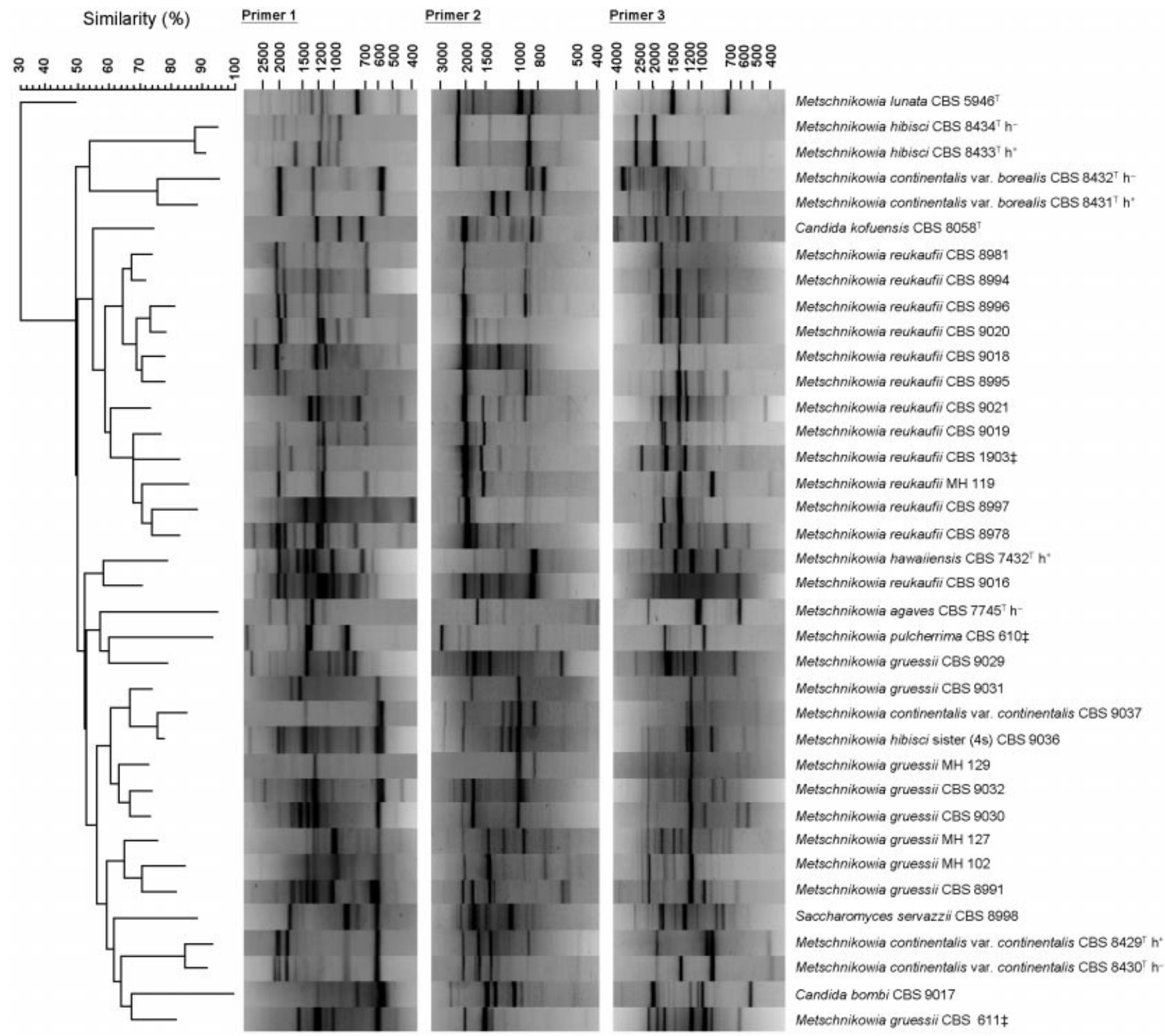

Fig. 1. Analysis of the RAPD-PCR patterns for the ascomycetous yeasts. Neighbour-joining analysis was performed using the similarity matrix generated from the densitometric curves produced from the gel tracks. The similarity matrix was calculated by using the pair-wise Pearson's correlation coefficient. The results of all three primers are combined in this analysis. Primer 1, 5'-ACGGTCTTGG-3'; Primer 2, 5'-TGCAGCGTGG-3'; Primer 3, 5'-GGGTAACGCC-3'. 7 , Reference strain; s, number of substitutions in the D1/D2 domain compared to the type strain of the closest related species. The size markers at the top of each set of images are in bp.

Although $M$. reukaufii, M. gruessii and Cystofilobasidium capitatum could be identified by their morphological characteristics in most cases, it must be emphasized that species determination based only on morphological criteria is inadequate for most yeast species.

\section{Molecular characterization}

Except for $M$. gruessii, M. reukaufii and Cystofilobasidium capitatum, the identities of all of the species listed in Table 1 were eventually determined by large- subunit rDNA D1/D2 domain sequence analysis. The conventional approach for species identification would have involved the determination of over 50 growth responses (Yarrow, 1998) - a very onerous task, especially for a laboratory whose primary concern is not yeast identification. Instead, the strains were subjected to RAPD-PCR, a simple and rapid method for yeast typing. Figs 1 and 2 show analyses of the results produced by this method. The banding patterns were used to construct trees from which it was hoped that species identification could be achieved, by connecting unknowns to authentic reference strains. However, the 


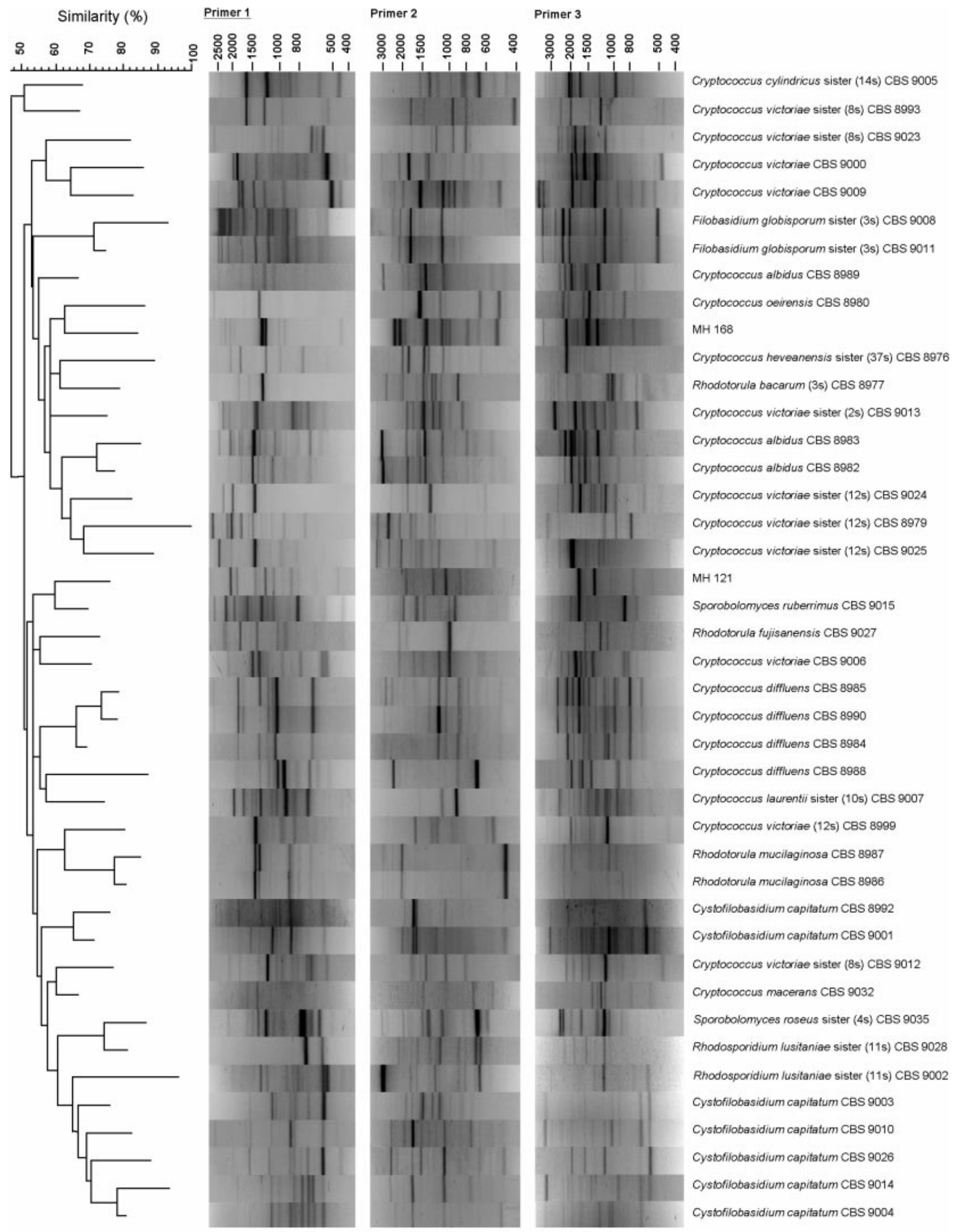

Fig. 2. For legend see facing page. 


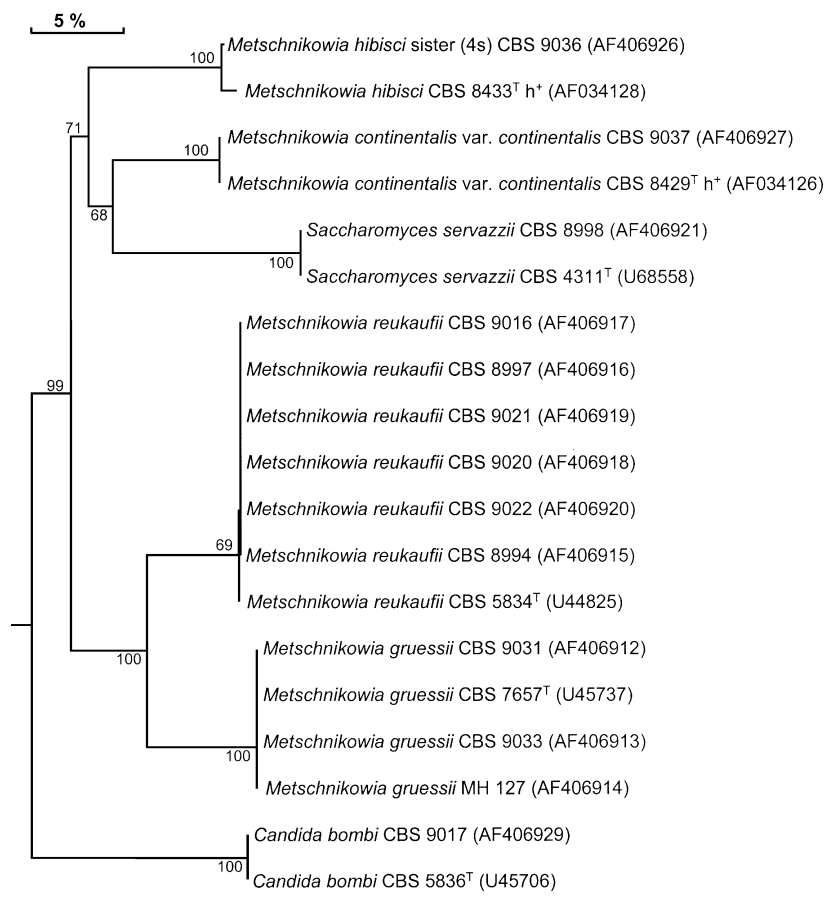

Fig. 3. Phylogenetic tree for the ascomycetous strains, constructed using the neighbour-joining method, generated using D1/D2 rDNA sequences. Only bootstrap values above $50 \%$ are shown (based on 1000 replications). The letter $s$ in parentheses with a number indicates the number of substitutions in the D1/D2 domain compared to the type strain of the closest related species.

cluster structure was generally weak and the banding patterns did not often fall into clearly recognizable, distinct classes. Analyses of D1/D2 sequences, based on the neighbour-joining method of tree reconstruction, for the same yeasts are shown in Fig. 3 and Fig. 4 , for the ascomycetous and basidiomycetous yeasts, respectively. Following the proposal of Kurtzmann \& Robnett (1997), all strains that showed more than two substitutions in the D1/D2 domain when compared to their closest related type strain (found in GenBank) were suspected of being sister species (Table 1). The number of substitutions between individual isolates and their nearest neighbours are shown in Table 1. Sister species of $M$. hibisci, Cryptococcus heveanensis (Groenewege) Baptist \& Kurtzman, Cryptococcus victoriae Montes et al. Cryptococcus laurentii (Kufferath) Skinner and Rhodosporidium lusitaniae Fonseca \& Sampaio were found, and these strains have a very high potential to represent new species. How- ever, the isolation of more strains and their full characterization in relation to known species is required before these strains can be described as new species.

According to the analysis of RAPD-PCR patterns, the ascomycetous strains CBS 9036 and CBS 9037 would have been viewed as slightly atypical strains of $M$. gruessii (Fig. 1). However, sequence analysis (Fig. 3) showed CBS 9036 and CBS 9037 to be sister species of $M$. hibisci and $M$. continentalis, respectively. Strain CBS 9036 showed only about $30 \%$ similarity to the type strains of $M$. hibisci (CBS $8433^{\mathrm{T}} \mathrm{h}^{+}$, CBS $8434^{\mathrm{T}}$ $\mathrm{h}^{-}$) upon the analysis of RAPD-PCR patterns, even though the two strains exhibited $99 \%$ similarity in the D1/D2 domain. Strain CBS 9016, which exhibited $100 \%$ sequence similarity to the other sequenced strains of $M$. reukaufii, appeared more closely related to the type strain of M. hawaiiensis (CBS $7432^{\mathrm{T}} \mathrm{h}^{+}$) and to the reference strain of $M$. gruessii (CBS 611) than to the reference strain of M. reukaufii (CBS 1903) in the analysis of the RAPD-PCR patterns (Fig. 1). In this analysis, Candida bombi Montrocher (CBS 9017), which belongs to the Starmerella clade (Rosa \& Lachance, 1998), appeared to be more closely related to $M$. continentalis var. continentalis than the varieties of $M$. continentalis were to each other. The RAPDPCR patterns of the reference strain used for $M$. gruessii (CBS 611) were more similar to those of the Candida bombi strain (CBS 9017) than to those of the other authentic strains of $M$. gruessii. Even though strain CBS 9021 showed 100\% D1/D2 sequence similarity to the other strains of M. reukaufii (Fig. 3), including the reference strain CBS 1903, its RAPDPCR patterns were more similar to those of the type strain of Candida kofuensis (CBS $8058^{\mathrm{T}}$; Fig. 1).

A significant discrepancy between the results of the RAPD-PCR and sequence analysis was found also for the basidiomycetous strains (Figs 2 and 4, respectively). In the RAPD-PCR analysis, strain CBS 8999 (Cryptococcus victoriae) was well separated from strains CBS 8979 and CBS 9025 (both Cryptococcus victoriae), and it clustered with strain CBS 9007 (Cryptococcus laurentii). However, strains CBS 8999 and CBS 9007 were quite distantly related on the basis of D1/D2 sequence data ( $89 \%$ similarity), whereas strains CBS 9025, CBS 8979 and CBS 8999 had identical sequences. The RAPD-PCR pattern of strain CBS 9006 (Cryptococcus victoriae; Fig. 2) showed less than $55 \%$ similarity with the RAPD-PCR patterns of strains CBS 9009 and CBS 9000 (both Cryptococcus victoriae), although all three strains were identical in their D1/D2 sequences to the type strain of Crypto-

Fig. 2. Analysis of the RAPD-PCR patterns for the basidiomycetous yeasts. Neighbour-joining analysis was performed using the similarity matrix generated from the densitometric curves produced from the gel tracks. The similarity matrix was calculated by using the pair-wise Pearson's correlation coefficient. Primer 1, 5'-ACGGTCTTGG-3'; Primer 2, 5'TGCAGCGTGG-3'; Primer 3, 5'-GGGTAACGCC-3'. The results of all three primers are combined in this analysis. A lowercase $s$ in parentheses with a number indicates the number of substitutions in the D1/D2 domain compared to the type strain of the closest related species. The size markers at the top of each set of images are in bp. 


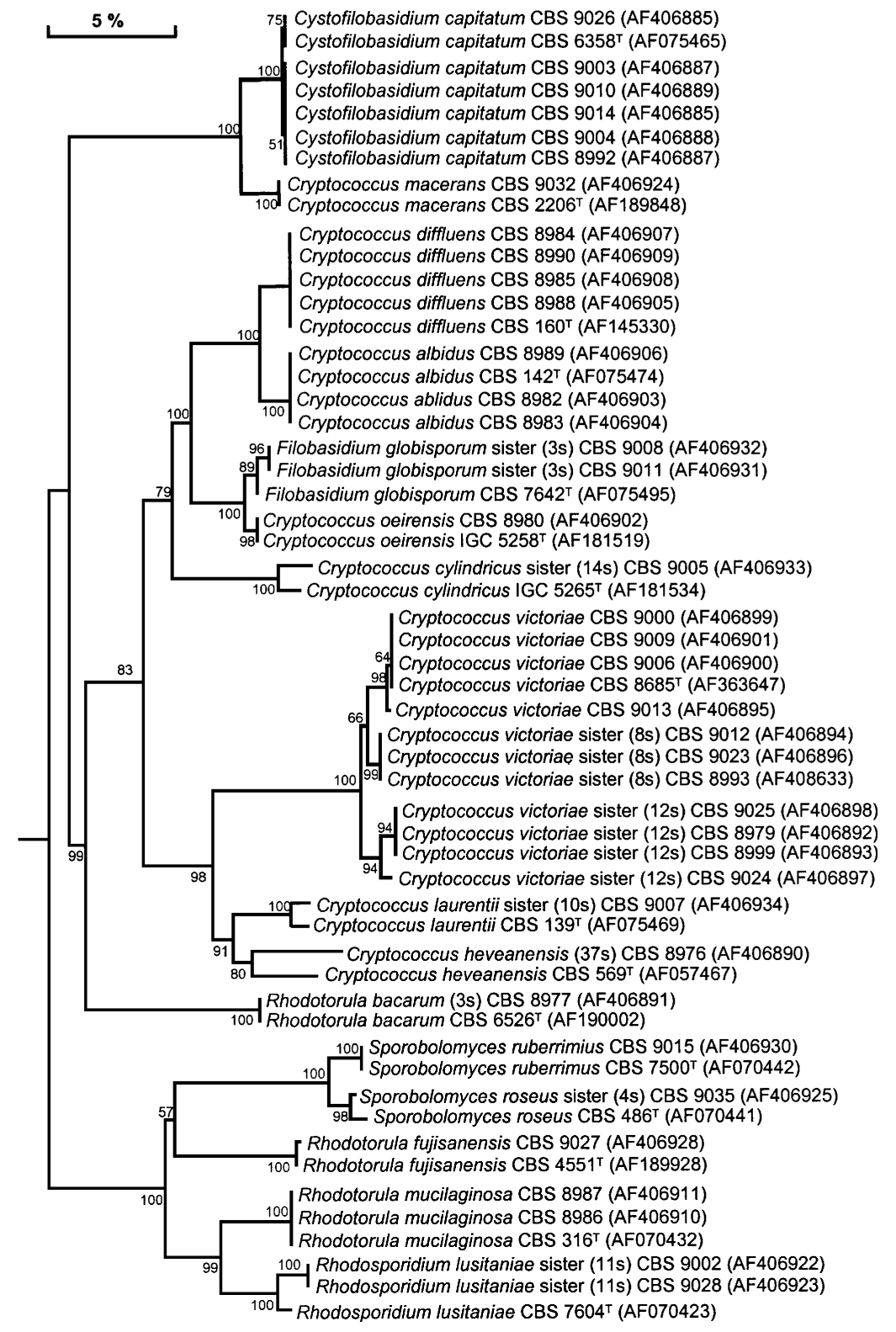

Fig. 4. Phylogenetic tree for the basidiomycetous strains, constructed using the neighbour-joining method, generated using D1/D2 rDNA sequences. Only bootstrap values above $50 \%$ are shown (based on 1000 replications). The letter $s$ in parentheses with a number indicates the number of substitutions in the D1/D2 domain compared to the type strain of the closest related species. coccus victoriae. In contrast to this finding, the RAPDPCR patterns of strain CBS 9006 showed more similarity to those of Rhodotorula fujisanensis (Soneda) Johnson \& Phaff strain CBS 9027 than to any other strain (Fig. 2). In the RAPD-PCR analysis, strain CBS 8992 did not cluster with the other sequenced strains of Cystofilobasidium capititatum, despite the fact that it exhibits $100 \%$ sequence similarity to strains CBS 9003, CBS 9010, CBS 9014 and CBS 9004 (Fig. 4). The same discrepancy between RAPD-PCR analysis and sequence analysis was found for the Cryptococcus albidus (Saito) Skinner strains CBS 8982, CBS 8983 and CBS 8989 (Figs 2 and 4).

Conflicting results have been reported before when multiple isolates of Cryptococcus neoformans from a single patient have been characterized by RAPD-PCR and other molecular typing techniques (Casadevall \&
Spitzer, 1995; Haynes et al., 1995). In contrast to the findings of various authors (e.g. Messner et al., 1994; Baleiras Couto et al., 1994; Mollnar et al., 1995; Lopandic et al., 1996; Romano et al., 1996; Prillinger et al., 1999; Naumova et al., 2000; Paramithiotis et al., 2000), we conclude that RAPD-PCR is not a reliable method for the determination or comparison of unknown yeast strains. We agree with de Barros Lopes et al. (1998) that strains producing distinct amplification patterns cannot be assumed to be different species, given that members of a species may be represented by several banding patterns. Our results support the view of De Filippis \& Magel (1998), in that the usefulness of RAPD-PCR for comparing individuals belonging to different species is low.

The background noise level in RAPD-PCR, which is inherent in this method (Messner et al., 1994), seems to 
be too high for the differentiation of strains and the assignment of strains to type strains. Various factors influence the RAPD-PCR patterns produced. The selection of target sites for amplification by the primers in the first cycles of the PCR does not depend only on the template sequence: the annealing of primers is also influenced by differences in the concentration of template DNA, $\mathrm{MgCl}_{2}$, dNTPs and primers, the purity and quality of the template DNA, the composition of the primer and the annealing temperature (Kwok et al., 1990; Rychlik et al., 1990; Rychlik, 1995; Erlich et al., 1991; Muralidharan \& Wakeland, 1993; Meunier \& Grimont, 1993; Micheli et al., 1994; Davin-Regli et al., 1995). Since these factors can never be completely standardized (Messner et al., 1994; Mollnár et al., 1995), and not all processes and mechanisms involved in RAPD-PCR are fully understood (Wolff et al., 1993), they may have a great effect on the occurrence of RAPD markers as well as differences of the template sequence in different samples.

False priming and other PCR artefacts may occur (Kwok et al., 1990; Sommer \& Tautz, 1989; Riedy et al., 1991) and, in respect to the low stringency of the RAPD-PCR method, amplification at imperfectly matching primer sites may occur frequently. At definite template concentrations, mismatches and the amplification of rare priming sites have been reported to be random events resulting in the non-reproducibility of RAPD profiles (Davin-Regli et al., 1995).

Other factors may influence the RAPD-PCR patterns in later parts of the reaction. One of these is the occurrence of hairpin loops. Such secondary structures within the PCR products influence the rate at which the different fragments are amplified after the first cycles. Caetano-Anollés et al. (1992) showed convincingly that only a subset of all the possible target sites for amplification that are determined by the primer sequence become a RAPD marker at the end of the reaction.

Other factors, such as the annealing temperature, extension time and number of cycles, affect the specificity of every PCR (Rychlik et al., 1990; Erlich et al., 1991). To prevent the influence of marginal differences in the temperature program, Baleiras Couto et al. (1994) recommended the installation of the thermocycler in a thermoregulated room. Among other things, Halmschlager et al. (1994) reported that the formation of amplification products depends on the thermocycling facilities and the individuals involved. Variations in RAPD-PCR patterns can also be associated with the brand of the enzyme used in different investigations (Meunier \& Grimont, 1993). One cannot guarantee the constant performance of a batch of Taq DNA polymerase or of a particular piece of PCR apparatus over the years (Meunier \& Grimont, 1993). To prevent variations in the reaction conditions, Messner et al. (1994) and Mollnár et al. (1995) proposed that all samples for a given investigation should be processed in a single thermocycler run. This would restrict the number of samples that can be compared in one investigation and would not allow the use of RAPD-PCR for large scale experiments, contrary to the claim made by Mollnár et al. (1995).

It is commonly claimed that methods such as RAPDPCR and amplified fragment length polymorphism (AFLP) analysis sample the whole genome randomly and therefore give a representative picture of the whole genome. Consequently, consistent results should be obtained by the two methods, and with different primers. At variance with this assumption, Ganter \& de Barros Lopes (2000) showed that RAPD-PCR and AFLP can result in significantly different trees and others have obtained different results with different primers (Haynes et al., 1995; Baleiras Couto et al., 1996; Joachim et al., 1997). We conclude that the numerous imponderables of RAPD-PCR make it impossible to gain reliable results with this method, at least as a means of identifying yeasts in ecological studies. The often described high resolution of the method may be the result of 'background noise' in a lot of cases.

Beside the lack of reproducibility associated with RAPD-PCR results, another disadvantage of this method is the lack of universally established guidelines for the selection of primers (Leung et al., 2000), standard methods for the interpretation of the data (Boekhout et al., 1997; Leung et al., 2000) and standard protocols for PCR, electrophoresis and the detection of banding patterns. Unless the method is standardized, the databases of different investigations are not comparable and it is not possible to assemble a general database of patterns for strain identification (Meunier \& Grimont et al., 1993). In each laboratory a new reference dataset must be generated. At least the type strains of all species considered must be included in each study. For the identification of unknown strains this leads to the paradoxical situation that one has to choose close relatives to strains whose genus is not known.

From our own data and the inconsistencies in the literature we conclude that, in agreement with de Barros Lopes (1998), the information obtained using PCR is clearly not as precise as sequencing. In contrast to RAPD-PCR, sequence analyses of the D1/D2 domain of the large-subunit rDNA turned out to be a fast, simple and completely reproducible method $(100 \%)$ for yeast identification. The correlation of $\mathrm{D} 1 / \mathrm{D} 2$ sequence divergence and species boundaries in ascomycetous and basidiomycetous yeast has been discussed sufficiently by Kurtzman \& Robnett (1997) and Fell et al. (2000). Since a complete dataset of the $\mathrm{D} 1 / \mathrm{D} 2$ domain for all described yeast species is available on the Internet (e.g. GenBank, EMBL) (Kurtzmann \& Robnett, 1998; Fell et al., 2000, and many other authors), it is usually possible to identify a single strain with only its sequence. As soon as one has a purified culture, it is possible to generate the D1/D2 sequence of a strain by amplifying the D1/D2 domain directly from whole cells, bypassing the DNA extraction procedure, within two days (Lachance et al., 
1999). For the discrimination of closely related strains or the analysis of intraspecific genetic diversity the sequences of the D7/D8 domain of the large-subunit rDNA, the intergenic spacers (IGSs) and 28S rDNA and the internally transcribed spacer (ITS) regions provide additional meaningful information (Fell et al., 2000; Lachance et al., 2000; Fonseca et al., 2000; Sugita et al., 2000). In view of the ever decreasing cost of sequencing and the reliability of the results it produces, contrasted with the various disadvantages of RAPD-PCR, the question arises as to why RAPDPCR is still frequently used in laboratories.

\section{ACKNOWLEDGEMENTS}

We acknowledge Vincent Robert (CBS, Uppsalalan 8, 3584 CT Utrecht, The Netherlands) and Dr Marc-André Lachance (University of Western Ontario, Department of Plant Sciences, London, Ontario N6A 5B7, Canada) for sending us the type strains of the yeasts used in this study. We thank Ralf Liese for his generous advice in the lab and Pablo Vinuesa for help with the interpretation of the RAPDPCR patterns.

\section{REFERENCES}

Baleiras Couto, M. M., van der Vossen, J. M. B. M., Hofstra, H. \& in't Veld, J. H. J. H. (1994). RAPD analysis: a rapid technique for differentiation of spoilage yeasts. Int J Food Microbiol 24, 249-260.

Baleiras Couto, M. M., Eijsma, B., Hofstra, H., in't Veld, J. H. J. H. \& van der Vossen, J. M. B. M. (1996). Evaluation of molecular typing techniques to assign genetic diversity among Saccharomyces cerevisiae strains. Appl Environ Microbiol 62, 41-46.

Boekhout, T., van Belkum, A., Leenders, A. C. A. P., Verbrugh, H. A., Mukamurangwa, P., Swinne, D. \& Scheffers, W. A. (1997). Molecular typing of Cryptococcus neoformans: taxonomic and epidemiological aspects. Int J Syst Bacteriol 47, 432-442.

Boutroux, L. (1881). Note sur la recherche des germes de bactéries dans les aux. Bull Soc Linn Normandie 5, 96-100.

Boutroux, M. L. (1884). Sur la conservation des ferments alcooliques dans la nature. Ann Sci Nat Bot 17, 145-209.

Caeteno-Anollés, G., Bassam, B. J. \& Gresshoff, P. M. (1992). Primer-template interactions during DNA amplification fingerprinting with single arbitrary oligonucleotides. Mol Gen Genet 235, 157-165.

Casadevall, A. \& Spitzer, E. D. (1995). Involvement of multiple Cryptococcus neoformans strains in a single episode of cryptococcosis and reinfection with novel strains in recurrent infection demonstrated by random amplification of polymorphic DNA and DNA fingerprinting. J Clin Microbiol 33, 1682-1683.

Davin-Regli, A., Abed, Y., Charrel, R. N., Bollet, C. \& de Micco, P. (1995). Variations in DNA concentrations significantly affect the reproducibility of RAPD fingerprint patterns. Res Microbiol 146, 561-568.

de Barros Lopes, M., Soden, A., Martens, A. L., Henschke, P. A. \& Langridge, P. (1998). Differentiation and species identification of yeasts using PCR. Int J Syst Bacteriol 48, 279-286.

de Filippis, L. \& Magel, E. (1998). Differentiation in genomic DNA extracted from bark and from wood of different zones in Robinia trees using RAPD-PCR. Trees 12, 377-384.

Eiskowitch, D., Lachance, M. A., Willis, P. G. K. S. \& CollinsThompson, D. L. (1990). The effect of the natural assemblage of microorganisms and selected strains of the yeast Metschnikowia reukaufi in controlling the germination of pollen of the common milkweed Asclepia syriaca. Can J Bot 68, 1163-1165.

Erlich, H. A., Gelfand, D. \& Sninsky, J. J. (1991). Recent advances in the polymerase chain reaction. Science 252, 1643-1651.
Fell, J. W., Boekhout, T., Fonseca, A., Scorzetti, G. \& StatzellTallman, A. (2000). Biodiversity and systematics of basidiomycetous yeasts as dertermined by large-subunit rDNA D1/D2 sequence analysis. Int J Syst Evol Microbiol 50, 1351-1371.

Fonseca, Á., Scorzetti, G. \& Fell, J. W. (2000). Diversity in the yeast Cryptococcus albidus and related species as revealed by ribosomal DNA sequence analysis. Can J Microbiol 46, 7-27.

Ganter, P. F. \& de Barros Lopes, M. (2000). The use of anonymous DNA markers in assessing worldwide relatedness in the yeast species Pichia kluyveri Bedford and Kudrjavzev. Can J Microbiol 46, 967-980.

Giménez-Jurado, G. (1992). Metschnikowia gruessii sp. nov. the teleomorph of Nectaromyces reufaufii but not of Candida reukaufii. Syst Appl Microbiol 15, 432-438.

Grüß, J. (1917/18). Die Anpassungen eines Pilzes (Anthomyces reukaufii) and den Blütenbau und den Bienenrüssel. Ber Dtsch Bot Ges 35, 746-762.

Grüß, J. (1927). Genetische und gärungsphysiologische Untersuchungen an Nektarhefen. Jahrb Wiss Bot 66, 109-182.

Guadet, J., Julien, J., Lafay, J. F. \& Brygoo, Y. (1989). Phylogeny of some Fusarium species, as determined by large-subunit rRNA sequence comparison. Mol Biol Evol 6, 227-242.

Halmschlager, E., Messner, R., Kowalski, T. \& Prillinger, H. (1994). Differentiation of Ophiostoma piceae and Ophiostoma quercus by morphology and RAPD analysis. Syst Appl Microbiol 17, 554-562.

Häne, B. G., Jäger, K. \& Drexler, H. G. (1993). The Pearson productmoment correlation coefficient is better suited for identification of DNA fingerprint profiles than band matching algorithms. Electrophoresis 14, 967-972.

Hautmann, F. (1924). Über die Nektarhefe Anthomyces reukaufii. Arch Protistenk 48, 212-245.

Haynes, K. A., Sullivan, D. J., Coleman, D. C., Clarke, J. C. K., Emilianus, R., Atkinson, C. \& Cann, K. J. (1995). Involvement of multiple Cryptococcus neoformans strains in a single episode of cryptococcosis and reinfection with novel strains in recurrent infection demonstrated by random amplification of polymorphic DNA and DNA fingerprinting. J Clin Microbiol 33, 99-102.

Joachim, A., Daugschies, A., Christensen, C. M., Bjørn, H. \& Nansen, P. (1997). Use of random amplified polymorphic DNApolymerase chain reaction for the definition of genetic markers for species and strains of porcine Oesophagostomum. Parasitol Res 83, 646-654.

Kurtzman, C. P. \& Robnett, C. J. (1997). Identification of clinically important ascomycetous yeasts based on nucleotide divergence in the $5^{\prime}$ end of the large-subunit (26S) ribosomal DNA gene. J Clin Microbiol 35, 1216-1223.

Kurtzman, C. P. \& Robnett, C. J. (1998). Identification and phylogeny of ascomycetous yeasts from analysis of nuclear large subunit (26S) ribosomal DNA partial sequences. Antonie Leeuwenhoek 73, 331-371.

Kwok, S., Kellogg, D. E., McKinney, N., Spasic, D., Goda, L., Levenson, C. \& Sninsky, J. J. (1990). Effects of primer-template mismatches on the polymerase chain reaction: human immunodeficiency virus type 1 model studies. Nucleic Acids Res 18, 999-1005. Kwong-Chung, K. J. (1998). Cystofilobasidium Oberwinkler \& Bandoni. In The Yeasts: a Taxonomic Study, 4th edn, pp. 646-653. Edited by C. P. Kurtzmann \& J. W. Fell. Amsterdam: Elsevier.

Lachance, M.-A. (1987). Approaches to yeast identification. In Yeast Biotechnology, pp. 33-51. Edited by D. R. Berry, I. Russell \& G. G. Stewart. London: Allen \& Unwin.

Lachance, M.-A. \& Pang, W. M. (1997). Predacious yeasts. Yeast 13, 225-232.

Lachance, M.-A., Bowles, J. M., Starmer, W. T. \& Barker, J. S. F. (1999). Kodamaea kakaduensis and Candida tolerans, two new ascomycetous yeast species from Australian Hibiscus flowers. Can J Microbiol 45, 172-177.

Lachance, M.-A., Starmer, W. T., Bowles, J. M., Phaff, H. J. \& Rosa, 
C. A. (2000). Ribosomal DNA, species structure, and biogeography of the cactophilic yeast Claviospora opuntiae. Can J Microbiol 46, 195-210.

Lachance, M.-A., Starmer, W. T., Rosa, C. A., Bowles, J. M., Barker, J. S. F. \& Janzen, D. H. (2001). Biogeography of the yeasts of ephemeral flowers and their insects. FEMS Yeast Res 1, 1-8.

Leung, W. K., Dassanayake, R. S., Yau, J. Y. Y., Jin, L. J., Yam, W. C. \& Samaranayake, L. P. (2000). Oral colonization, phenotypic, and genotypic profiles of Candida species in irradiated, dentate, xerostomic nasopharyngeal carcinoma survivors. J Clin Microbiol 38, 2219-2226.

Lodder, J. \& Kreger-van Rij, N. J. W. (1952). The Yeasts : a Taxonomic Study. Amsterdam: North Holland.

Lopandic, K., Prillinger, H., Molnár, O. \& Giménez-Jurado, G. (1996). Molecular characterization and genotypic identification of Metschnikowia species. Syst Appl Microbiol 19, 393-402.

Martin, H. H. (1954). Beitrag zur Kenntnis der Morphologie und Physiologie der Nektarhefe Candida reukaufii (Grüß) Diddens et Lodder. Arch Mikrobiol 20, 141-162.

Messner, R., Prillinger, H., Altmann, F., Lopandic, K., Wimmer, K., Molnár, O. \& Weigang, F. (1994). Molecular characterization and application of random amplified polymorphic DNA analysis of Mrakia and Sterigmatomyces species. Int J Syst Bacteriol 44, 694-703.

Meunier, J.-R. \& Grimont, P. A. D. (1993). Factors affecting reproducibility of random amplified polymorphic DNA fingerprinting. Res Microbiol 144, 373-379.

Micheli, M. R., Bova, R., Pascale, E. \& D'Ambrosio, E. (1994). Reproducible DNA fingerprinting with the random amplified polymorphic DNA (RAPD) method. Nucleic Acids Res 22, 1991-1922.

Mollnár, O., Messner, R., Prillinger, H., Stahl, U. \& Slavikova, E. (1995). Genotypic identification of Saccharomyces species using random amplified polymorphic DNA analysis. Syst Appl Microbiol 18, 136-145.

Muralidharan, K. \& Wakeland, E. K. (1993). Concentration of primer and template qualitively affects products in random-amplified polymorphic DNA PCR. Biotechniques 14, 362-364.

Naumova, E. S., Naumova, G. I. \& Molina, F. I. (2000). Genetic variation among European strains of Saccharomyces paradoxus: results from DNA fingerprinting. Syst Appl Microbiol 23, 86-92.

Oberwinkler, F., Bandoni, R., Blanz, P. \& Kisimova-Horovitz, L. (1983). Cystofilobasidium: a new genus in the Filobasidiaceae. Syst Appl Microbiol 4, 114-122.

O'Donell, K. (1993). Fusarium and its near relatives. In The Fungal Holomorph: Mitotic, Meiotic and Pleomorphic Speciation in Fungal Systematics, pp. 225-233. Edited by D. R. Reynolds \& J. W. Taylor. Wallingford, UK: CAB International.

Paramithiotis, S., Müller, M. R. A., Ehrmann, M. A., Tsakalidou, E., Seiler, H., Vogel, R. \& Kalantzopoulos, G. (2000). Polyphasic identification of wild yeast strains isolated from Greek sourdoughs. Syst Appl Microbiol 23, 156-164.

Pitt, J. I. \& Miller, M. W. (1968). Sporulation in Candida pulcherrima, Candida reukaufi and Chlamydozyma species: their relationships with Metschnikowia. Mycologia 60, 663-685.

Pitt, J. I. \& Miller, M. W. (1970). Speciation in the yeast genus Metschnikowia. Antonie Leeuwenhoek 36, 357-381.

Price, C. W., Fuson, G. B. \& Phaff, H. J. (1978). Genome comparison in yeast systematics: delimitation of species within the genera Schwanniomyces, Saccharomyces, Debaryomyces, and Pichia. Microbiol Rev 42, 161-193.

Prillinger, H., Molnár, O., Eliskases-Lechner, F. \& Lopandic, K. (1999). Phenotypic and genotypic identification of yeasts from cheese. Antonie Leeuwenhoek 75, 267-283.

Rademaker, J. L. W., Louws, F. J., Rossbach, U., Vinuesa, P. \& de Brujin, F. J. (1999). Computer-assisted pattern analysis of molecular fingerprints and database construction. In Molecular Microbial Ecology Manual, 7.1.3, pp. 1-33. Dordrecht/Boston/London: Kluwer Academic.

Reukauf, E. (1911/12). Nektarhefen. Die Kleinwelt 3, 25-26.

Riedy, M. F., Hamilton, W. J. \& Aquadro, C. F. (1991). Excess of nonparental bands in offspring from known primate pedigrees assayed using RAPD PCR. Nucleic Acids Res 20, 918.

Romano, A., Casaregola, S., Torre, P. \& Gaillardin, C. (1996). Use of RAPD and mitochondrial RFLP for typing of Candida zeylanoides and Debaryomyces hansenii yeast strains isolated from cheese. Syst Appl Microbiol 19, 255-264.

Rosa, C. A. \& Lachance, M.-A. (1998). The yeast genus Starmarella gen. nov. and Starmarella bombicola sp. nov., the teleomorph of Candida bombicola (Spencer, Gorin \& Tullock) Meyer \& Yarrow. Int J Syst Bacteriol 48, 1413-1417.

Rychlik, W. (1995). Primer efficiency in PCR. Biotechniques 18, 84-89. Rychlik, W., Spencer, W. J. \& Rhoads, R. E. (1990). Optimization of the annealing temperature for DNA amplification in vitro. Nucleic Acids Res 18, 6409-6412.

Schoellhorn, K. (1919). Sur la fermentation de quelques levures des nectares de plantes d'hiver. Bull Soc Bot Genéve 11, 154-190.

Schuster, V. \& Úhlela, V. (1913). Studien über Nektarorganismen. Ber Dtsch Bot Ges 13, 129-139.

Sommer, R. \& Tautz, D. (1989). Minimal homology requirements for PCR primers. Nucleic Acids Res 17, 6749.

Stelling-Decker, N. M. (1931). Die Hefesammlung des ' Centraalbureau voor Schimmelcultures' Beiträge zu einer Monographie der Hefearten, 1. Teil, Die Sporogenen Hefen. Amsterdam: Drukkerij.

Sugita, T., Takashima, M., Ikeda, R., Nakase, T. \& Shinoda, T. (2000). Intraspecies diversity of Cryptococcus laurentii as revealed by sequences of internal transcribed spacer regions and 28S rRNA gene and taxonomic position of C. laurentii clinical isolates. J Clin Microbiol 38, 1468-1471.

Sydow, H. \& Sydow, P. (1918). Mykologische Mitteilungen. Ann Mycol 16, 240-248.

Thompson, J. D., Higgins, D. G. \& Gibson, T. J. (1994). CLuSTAL W: Improving the sensitivity of progressive multiple sequence alignment through sequence weighting, position-specific gap penalties and weight matrix choice. Nucleic Acids Res 22, 4637-4680.

Vinuesa, P., Rademaker, J. L. W., de Brujin, F. J. \& Werner, D. (1998). Genotypic characterization of Bradyrhizobium strains nodulating endemic woody legumes of the Canary Islands by PCR-restriction fragment length polymorphism analysis of genes encoding 16S rRNA (16S rDNA) and 16S-23S rDNA intergenic spacers, repetitive extragenic palindromic PCR genomic fingerprinting, and partial $16 \mathrm{~S}$ rDNA sequencing. Appl Environ Microbiol 64, 2096-2104.

Vobis, G. (1991). Morphological approaches to rapid recognition of sporangiate and non-sporangiate genera. In Actinoplanetes and Maduromycetes (Isolation and Characterization). International Symposium on Biology of Actinomycetes, pp. 7-20. University of Wisconsin.

Vobis, G. (1992). The genus Actinoplanes and related genera. In The Prokaryotes, 2nd edn, pp. 1029-1060. Edited by A. Balows, H. G. Trüper, M. Dworkin, W. Harder \& K.-H. Schleifer. New York: Springer-Verlag.

Welsh, J. \& McClelland, M. (1990). Fingerprinting genomes using PCR with arbitrary primers. Nucleic Acids Res 24, 7213-7218.

Williams, J. G. K., Kubelik, A. R., Livak, K. J., Rafalski, J. A. \& Tingey, S. V. (1990). DNA polymorphisms amplified by arbitrary primers are useful as genetic markers. Nucleic Acids Res 22, 6531-6535. Wolff, K., Schoen, E. D. \& Peters-Van Rijn, J. (1993). Optimizing the generation of random amplified polymorphic DNAs in Chrysanthemum. Theor Appl Genet 86, 1033-1037.

Yarrow, D. (1998). Methods for the isolation and identification of yeasts. In The Yeasts, a Taxonomic Study, 4th edn, pp. 77-100. Edited by C. P. Kurtzmann \& J. W. Fell. Amsterdam: Elsevier. 